\title{
Antonio CUSSEN, El milenio según Virgilio, Santiago de Chile, Ediciones Tácitas, 2018, 3 volúmenes, 495, 386 y 209, ISBN 978- 956-379-068-9
}

\author{
FRANCISCO GARCÍA JURADO \\ Universidad Complutense \\ ORCID: http://orcid.org/0000-0002-3106-1178 \\ pacogj@ucm.es
}

DOI: https://doi.org/10.24197/mrfc.34.2021.257-260

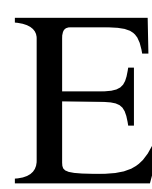

l año de 2018, el sello chileno Ediciones Tácitas dio a las prensas una monumental obra en tres volúmenes que lleva el título general de El milenio según Virgilio. Dentro de una caja-estuche se encuentran los tres

tomos, el primero de los cuales contiene un voluminoso estudio-ensayo, el segundo una edición-reconstrucción muy particular del texto latino de la Eneida y, finalmente, el tercero y menos voluminoso nos ofrece unas notas complementarias a tal edición. Por lo demás, se trata de una edición formalmente muy cuidada que contribuye a que la lectura se vuelva un acto agradable.

La primera vez que tuve noticia de esta obra fue gracias a un correo electrónico del profesor Hugo Bauzá, que me anticipaba, asimismo, su reseña publicada en la revista Nova Tellus. Me pareció sorprendente, ya de entrada, la circunstancia de que, a día de hoy, pueda publicarse una obra que anuncia el "descubrimiento" de un código secreto concebido por Virgilio dentro de su obra magna, la Eneida. Sucintamente, de acuerdo con el planteamiento de Antonio Cussen, Virgilio habría configurado un "templo verbal" o "poema calendario" con la intención de cifrar el ciclo que va desde la llegada de Eneas a Accio hasta la posterior victoria de Augusto sobre Marco Antonio y Cleopatra un milenio después, también en Accio.

Antonio Cussen, autor de un libro clásico acerca de Bolívar y Andrés Bello, y que ya en su momento se interesó por los paralelismos antiguos y modernos entre gobernante e intelectual, estudia ahora con sumo detalle la relación planteada entre Augusto y Virgilio. Así pues, Virgilio habría dejado escrita en clave una suerte de historia paralela basada en las afinidades entre Eneas y el emperador, si bien en cierto momento la muerte de Marcelo el Joven habría truncado, por así decirlo, el propósito inicial de la Eneida. Este funesto suceso, que daba al traste con las esperanzas puestas en la sucesión de Augusto, habría obligado a Virgilio a cambiar el propósito de su propia historia acerca de la llegada de los troyanos al Lacio. La Eneida sería, en este sentido, un ejemplo perfecto de "doble historia": la de Eneas y la del primer emperador de Roma.

Muchas ideas me vinieron a la cabeza ante un planteamiento semejante, debatiéndome básicamente entre el escepticismo y la curiosidad. Tras la noticia que 
tuve de la obra de Cussen gracias a Hugo Bauzá, se dio, asimismo, la circunstancia de que la Delegación de Madrid de la Sociedad Española de Estudios Clásicos me invitara a participar en sus jornadas de otoño de 2020. Se me pidió que hablara acerca de la Eneida, por lo que elegí un tema harto sugerente: "La cara oculta de la Eneida". Mi propósito era elegir algunas de las más importantes lecturas de carácter hermético que se habían hecho en torno al poema de Eneas, tanto antiguas como modernas. Elegí cuatro aspectos que me parecían muy significativos, como son las Suertes Virgilianas, el problema de la salida de los infiernos por la puerta de los sueños falsos, la singular lectura milenarista y regeneracionista que en el siglo XIX llevó a cabo el pensador social Pier Joseph Proudhon (lectura a la que ya había dedicado un artículo previo), y, finalmente, la lectura de un Virgilio pesimista propuesta por los virgilianistas norteamericanos de la llamada "Escuela de Harvard". Como puede verse, elegí dos hermetismos antiguos, básicamente dos asuntos clásicos, y otros dos modernos. De los modernos, uno corresponde al mismo siglo XIX y otro se refiere a una de las líneas interpretativas acerca de Virgilio más influyentes de finales del siglo XX. En lo que respecta a esta interpretación pesimista de la Eneida, es fundamental que observemos su afán de desvelar una lectura oculta, considerada como atemporal y no tanto en calidad de fruto de las nuevas circunstancias en que se leyó a Virgilio tras los totalitarismos de la primera mitad del siglo XX. De esta forma, la llamada Escuela de Harvard, no obstante su prestigio académico, ofrece en su exégesis unas propiedades herméticas de las que tampoco es ajena buena parte de la moderna crítica literaria.

No me costó mucho esfuerzo intuir que Antonio Cussen se adscribía, cuando menos de una forma indirecta, a esta línea de interpretación pesimista donde asistimos a una suerte de "resistencia pasiva" ejercida por Virgilio ante un Augusto que desea a toda costa su inmortalidad. Las páginas de Hermann Broch y su novela órfica La muerte de Virgilio afloran en calidad de precursoras de esta línea interpretativa, según la cual Virgilio habría querido quemar su obra cumbre no tanto a causa de las razones de imperfección aducidas por algunos de los antiguos biógrafos del poeta, sino justamente como una manera de privar a Augusto de su propia posteridad. Insistimos en el hecho de que este tipo de lecturas resultan harto sugerentes, pero están sujetas a una inquietante interpretación que intenta hacernos ver que se ha desvelado un código o intención secretos.

Me pareció oportuno e interesante, ya que por aquel entonces disponía tan sólo de la versión electrónica de dos de los volúmenes editados por Cussen, incluir su novedosa obra dentro de este apartado de mi estudio, sobre todo a tenor del propio planteamiento propuesto, y que él mismo explica de la manera siguiente, a partir de una clara idea de fundación que está presente en el propósito inicial de la Eneida:

Fundar una especie de dinastía divina -los Césares- a través de la cual el nuevo imperio quedara unido a los orígenes míticos del pueblo romano, que son las glorias de Eneas tras la caída de Troya. Ahora, lo que yo planteo es que pretende mucho más que eso, porque concibe el comienzo del imperio como el comienzo de un nuevo 
milenio. Y con eso, lo que en definitiva quiere Virgilio es fundar un orden terrenal que sea la imagen de un cosmos que funciona. Ni más ni menos. Esa intención de fundar un nuevo milenio es lo que da coherencia a todos los códigos numéricos y verbales de este gran criptograma.

De la misma forma en que los estudiosos de la Escuela de Harvard habían tratado de encontrar una segunda lectura oculta de la Eneida, donde el pesimismo da cuenta de la propia decepción que Augusto había creado sobre las expectativas del poeta, Cussen, en mi opinión, llega a sistematizar hasta tal punto esta lectura que incluso sostiene que la Eneida, lejos de ser un poema imperfecto, supone un cómputo exacto, letra a letra, del "milenio" ya referido. El propósito de demostrar que Virgilio había compuesto un poema "perfecto" lleva a Cussen a una singularísima edición del poema latino, desprovisto de cualquier signo de puntuación. De esta forma, Cussen intenta reconstruir el texto virgiliano tal como, a su juicio, pudo haber sido concebido inicialmente por Virgilio, letra a letra. Para ello, recurre a la inclusión de algunos de los versos que habían quedado fuera (en opinión de Cussen, a causa de la censura ejercida por el propio Augusto), al interpretarse como parte de una tradición indirecta, y considerando, asimismo, que los versos incompletos del poema son intencionales y no versos inacabados. De la dimensión numérica que tiene la obra de Virgilio sabemos, sobre todo, gracias a estudios dedicados a sus Bucólicas, en lo que respecta a las lecturas pitagóricas que se han planteado sobre tales églogas, y que serían fruto del interés que Virgilio sintió por la matemática desde sus tiempos de formación. Tales planteamientos regresan, ahora magnificados en forma de cómputo exhaustivo, a este nuevo análisis de la Eneida.

Cussen defiende, en suma, que la Eneida encierra un mensaje secreto que, como ya antes señalé, contaría, a partir del libro tercero del poema, la historia de Augusto en la clave de Eneas. Uno y otro serían instrumentos de la Historia, con mayúscula, y tanto el uno como el otro darían inicio a sendos milenios, especialmente a partir de sus respectivas sucesiones. En el caso de Eneas, se trataría de Ascanio/Julo y, en el caso de Augusto, del malogrado y joven Marcelo. Sin embargo, la prematura muerte de éste, que nos relata el propio Anquises en los infiernos mediante el famoso verso $\mathrm{Si}$ qua fata aspera rumpas! Tu Marcellus eris, va a quebrar el propio plan de Virgilio, que ve frustradas sus esperanzas con esta desaparición. Es por ello, según Cussen, por lo que el personaje de Ascanio se difumina en los últimos libros del poema. Ascanio no puede morir, naturalmente, en paralelo con la otra historia, y esto provoca que aparezca el personaje de la amazona Camila, aliada de Turno. La cruel muerte de la joven y valiente Camila daría cuenta, pues, de esta quiebra en los propósitos virgilianos.

He leído el estudio de Antonio Cussen, casi 500 páginas, con sumo placer, así como el volumen menos voluminoso dedicado a las notas complementarias a su edición de la Eneida. Soy consciente de que este tipo de planteamientos discurren inevitablemente por los peligrosos filos de la fascinación y la sospecha. Si hablamos de un código secreto de la Eneida, Cussen recurre a todo el aparato filológico del 
virgilianismo para desvelarlo y demostrarlo. Mi duda surge, no obstante, en torno a la naturaleza de este código, es decir, si se trata de una entidad hermética, oculta y debida a la propia intención del poeta, o si es fruto del ejercicio hermenéutico llevado a cabo por un estudioso moderno, en la línea de los estudiosos de la Escuela de Harvard. Dicho de otra forma: ¿este "código" existe a priori o a posteriori? $¿$ ¿Pertenece a la primigenia intentio auctoris o a la posterior intentio lectoris? Creo que aquí es donde se pueden debatir no sólo argumentos, sino también nuestras propias actitudes ante hechos de esta naturaleza. Habrá quien apasionadamente quiera creer en la intencionalidad virgiliana de dejarnos un código oculto, así como quien, de manera más escéptica, considere que tales planteamientos pertenecen, más bien, a la voluntad de los exégetas y lectores.

En cualquier caso, considero que la obra de Antonio Cussen es todo un monumento al virgilianismo. El autor demuestra un conocimiento exquisito de la constitución del texto virgiliano, y me gustaría saber cuál es la opinión que las páginas de Cussen puedan merecer a los virgilanistas europeos. Se trata de una obra que no nos dejará en absoluto indiferentes, al margen de nuestras convicciones y actitudes. No en vano, estamos ante un trabajo gestado a lo largo de una intensa vida dedicada al estudio de Virgilio. Si no me equivoco, mi texto es la primera reseña que se hace en el viejo continente. 